\title{
Componentes da produção e qualidade de sementes dos cultivares marandu e xaraés de Brachiaria brizantha (Hochst. ex A. Rich.) Stapf colhidas por varredura manual ou mecanizada
}

\author{
Components of seed production of two cultivars of Brachiaria \\ brizantha (Hochst. ex A. Rich.) Stapf haverst by manual or \\ mechanical sweeping
}

\author{
Danilo Gusmão de Quadros ${ }^{1 *}$; Alexandro Pereira Andrade ${ }^{2}$; \\ Gina Carla de Oliveira ${ }^{3}$; Eduardo Pereira Oliveira ${ }^{3}$; Eder Stolben Moscon ${ }^{4}$
}

\section{Resumo}

Objetivou-se com este trabalho avaliar os componentes da produção e a qualidade de sementes dos cvs. Marandu e Xaraés de Brachiaria brizantha (Hochst. ex A. Rich.) Stapf nos cerrados baianos, colhida por varredura manual ou mecanizada. Foi utilizado delineamento inteiramente casualizado, com 20 repetições, quantificando a densidade de perfilhos reprodutivos, o número de rácemos/perfilho, comprimento do rácemo basal, número de espiguetas/rácemo e produtividade de sementes puras/ha, utilizando um quadrado de $1 \mathrm{~m}^{2}$ em campo de produção com 320 e 80 ha dos cvs. Xaraés e cv. Marandu, respectivamente, na Fazenda Sagrillo, município de Barreiras, oeste do Estado da Bahia, com avaliações de campo entre maio e junho de 2008. As sementes colhidas por varredura manual e mecanicamente foram analisadas quanto à pureza, germinação e vigor de plântula a três profundidades de semeadura em caixa de areia $(1,2$ e $4 \mathrm{~cm})$. Os dados foram analisados estatisticamente no programa ASSISTAT, assumindo como significativas diferenças entre médias cujos valores de $\mathrm{F}$ forem menores que $0,05 \%$, pelo teste Tukey. A cv. Xaraés apresentou maior densidade de perfilhos reprodutivos $\left(206 / \mathrm{m}^{2}\right)$, rácemos em maior número $(7,25)$ e mais compridos $(15,8 \mathrm{~cm})$ que o cv. Marandu $\left(100\right.$ perfilhos $/ \mathrm{m}^{2}, 6,80$ rácemos/perfilho e 14,9 cm/rácemo, respectivamente). Entretanto, o número de espiguetas por rácemo foi semelhante (50,8 unidades). A produtividade de sementes puras foi maior no cv. Xaraés (188 kg/ha) que no cv. Marandu (154 kg/ha). A germinação na caixa de areia não diferiu entre os cultivares, método de colheita, ou profundidade de semeadura. Todavia, o vigor de plântula diminuiu com o aumento da profundidade de semeadura de 1 e $2 \mathrm{~cm}$ para $4 \mathrm{~cm}$. O cv. Xaraés apresentou componentes da produção de sementes mais favoráveis resultando em maior produtividade, enquanto a qualidade não diferiu entre cultivares ou método de colheita.

Palavras-chave: Espiguetas, Poaceae, rácemos

\footnotetext{
Abstract

The objective of this study was to evaluate the seed production compounds and productivity of seeds of cvs. Marandu and Xaraés of Brachiaria brizantha (Hochst. ex A. Rich.) Stapf harvest by manual or mechanical sweeping. There was used completely randomized design, with 20 replications, quantifying

${ }^{1}$ Prof. da Faculdade de Agronomia, Universidade do Estado da Bahia, UNEB, Campus IX, BR 242, km 04, s/n. Lot. Flamengo, Barreiras, Bahia, BA. E-mail: uneb_neppa@yahoo.com.br

${ }^{2}$ Doutorando em Zootecnia, UNEB, Itapetinga, Bahia, BA. E-mail: alexandro_andrade@hotmail.com

${ }^{3}$ Engenheiros Agrônomos da Faculdade de Agronomia, UNEB, Campus IX, Barreiras, Bahia, BA. E-mail: ginacoliver@yahoo. com.br

${ }^{4}$ Discente da Faculdade de Agronomia, UNEB, Campus IX, Barreiras, Bahia, BA. E-mail: hederstolben@hotmail.com

* Autor para correspondência
} 
reproductive tillers density, number of racemes/tiller, the length of basal raceme, number of spikelets / raceme, and the pure seed productivety/ha, using squares of $1 \mathrm{~m}^{2}$ in the seed production field with 320 and 80 ha sowing with cvs. Xaraés and Marandu, respectively, in the Sagrillo Farmer, Barreiras, western Bahia State-Brazil, with samples occurring from May to Jun of 2008. The seeds harvest manually handle were analyzed in pureness, germination, and seedling vigor under three depths in sand box (1,2 and, 4 $\mathrm{cm})$. The data were statistically analyzed by ASSISTAT program, assuming as significative differences between averages when $\mathrm{F}$ values were lower than 0.05 by the test Tukey. The $\mathrm{cv}$. Xaraés showed more reproductive tiller density $\left(206 / \mathrm{m}^{2}\right)$, higher number of racemes $(7.25)$ and more length per raceme $(15.8$ $\mathrm{cm}$ ) than the $\mathrm{cv}$. Marandu (100 tillers $/ \mathrm{m}^{2}, 6.80$ racemes/tiller e $14.9 \mathrm{~cm} /$ raceme, respectively). However, the number of spikelets by raceme was the same (50.8 units). The pure seed productivity was higher in the cv. Xaraés $(188 \mathrm{~kg} / \mathrm{ha})$ than the $\mathrm{cv}$. Marandu $(154 \mathrm{~kg} / \mathrm{ha})$. Germination in sand was not different between cultivars, harvest method, or depth of seed. However, seedling development decreased with increase of seed depth from 1 and $2 \mathrm{~cm}$ to $4 \mathrm{~cm}$. The $\mathrm{cv}$. Xaraés was superior considering the seed production compounds, resulting in higher seed productivity, while quality did not differ between cultivars or harvest method.

Key words: Spikelets, Poaceae, racemes

\section{Introdução}

O Brasil tem em torno de 100 milhões de hectares de pastagens cultivadas. Caso sejam reformadas $10 \%$ dessa área anualmente, considerando $12 \mathrm{~kg}$ de sementes comerciais/ha, seriam necessárias 120 mil toneladas de sementes (EUCLIDES et al., 2010).

Capins do gênero Brachiaria são os mais plantados no País, sendo bastante utilizados na cria, recria e engorda de gado de corte. Adaptam-se às mais variadas condições de solo e clima, ocupando espaço cada vez maior nos cerrados, com vantagens sobre outras espécies, devido a proporcionar produções satisfatórias de forragem em solos com baixa a média fertilidade (SOARES FILHO, 1994).

É incontestável a grande contribuição que o gênero Brachiaria trouxe para a pecuária de corte e de leite no Brasil. A expansão de pastagens em solos de baixa fertilidade nos Cerrados brasileiros com espécies desse gênero, principalmente Brachiaria decumbens (Stapf.), que permitiu a ocupação pecuária da região durante a década de 70. A expansão de novas áreas e a reforma de pastagens provocou aumento da demanda por sementes forrageiras, um estímulo cada vez maior para implantação dos campos de produção de sementes fiscalizadas, assim como a busca de sementes com maior índice de pureza e germinação (ANDRADE, 1994).
Segundo Euclides et al. (2010), estima-se que $60 \%$ da produção de sementes no Brasil sejam de $B$. brizantha, sendo que $90 \%$ das sementes exportadas são de quatro cultivares de Brachiaria spp.

Várias técnicas têm sido utilizadas para colheita de sementes de plantas forrageiras tropicais. Em todos os casos, contudo, cuidados devem ser tomados requerendo-se padrão de pureza com o mínimo de perdas de sementes e tempo (ILCA, 1994).

Colheita de sementes na inflorescência ou no solo por varredura são os dois métodos mais utilizados em espécies de capim do gênero Brachiaria spp. no Brasil. A adoção de um ou outro método é dependente da espécie cultivada, das atividades desenvolvidas na propriedade, da disponibilidade de mão-de-obra e/ou maquinaria e da tradição regional (ANDRADE, 1994).

A varredura manual de sementes é um método tradicional associado às leguminosas, mas também é praticado com algumas gramíneas, alcançando alto rendimento, germinação e vigor, promovendo estabelecimento da pastagem mais rápido $\mathrm{e}$ uniforme (LOCK; SOUZA, 1999). Segundo esses autores, o trabalho requerido tem sido grandemente reduzido por meio da mecanização. 
O método da varredura consiste em recolher mecanicamente todas as sementes produzidas pelas plantas que caíram sobre a superfície do solo juntamente com as impurezas. O método inicia-se fazendo o corte das plantas com lâmina segadeira acoplada ao trator, seguida do seu enleiramento, o qual pode ser feito à mão (com 'garfos') ou com ancinho rotativo, também acoplado ao trator ou inserido como kit à frente de colhedoras de grãos. A partir daí, inicia-se o processo da varredura mecânica de todo o material acumulado sobre a superfície do solo por máquinas especializadas, as quais estão disponíveis no mercado, também acopladas ao trator, com ótima eficiência e praticidade, mas limitada quanto ao rendimento (JOSÉ, 2009).

Segundo Maschietto, Novembre e Silva (2003), o método de varredura manual ou mecanizada permite maior obtenção de sementes que, embora de menor pureza física, apresentam maior qualidade fisiológica que as provenientes dos métodos da inflorescência ("no cacho").

$\mathrm{O}$ oeste baiano tornou-se a principal fronteira agrícola do Estado da Bahia. Nas décadas de 80 e 90 a região conheceu uma expansão agropecuária sem precedentes, devido ao acréscimo significativo nas áreas de grãos, cultivos perenes e na agricultura irrigada. Segundo dados da Associação dos Irrigantes da Bahia - AIBA (2009), na safra 2002/2003 a área plantada de capim destinado à produção de sementes era de 10.000 ha, com uma produtividade de $350 \mathrm{~kg} /$ ha. Já na safra 2008/2009 essa área saltou para 26.400 ha e com produtividade de $450 \mathrm{~kg} / \mathrm{ha}$. Na estimativa de safra 2010/2011, a área plantada é de $40 \mathrm{mil} \mathrm{ha,} \mathrm{com} 450 \mathrm{~kg} / \mathrm{ha}$ de rendimento, que resulta em 18 mil toneladas produzidas na região (AIBA, 2011). A região apresenta grande potencial para a produção de sementes de plantas forrageiras, graças às suas excelentes condições climáticas, edáficas e topográficas.

No oeste do estado da Bahia, a colheita por varredura mecanizada domina o método utilizado, com $73 \%$ de maneira exclusiva e mais $9 \%$ combinada (OLIVEIRA et al., 2010). Entretanto, a colheita por varredura manual poderia ser uma maneira de geração de renda na agricultura familiar local, porém até agora pouco explorada. O objetivo do presente trabalho foi de avaliar as técnicas de colheita por varredura manual ou mecanizada de sementes dos cultivares Marandu e Xaraés de Brachiaria brizantha (Hochst. ex A. Rich.) Stapf mensurando componentes da produção e qualidade.

\section{Material e Métodos}

O trabalho foi realizado na Fazenda Sagrillo, localizada na região das Placas, município de Barreiras, região fisiográfica de cerrados da Bahia, nos meses de março a abril de 2008. O solo predominante é classificado como areia quartzosa. A topografia e textura são favoráveis à mecanização, embora as propriedades químicas necessitem de correção para produção tecnificada. A propriedade compreende uma área de 400 ha destinados à produção de sementes de Brachiaria brizantha cvs. Marandu e Xaraés, semeadas no ano de 2005, sendo 320 ha do cv. Xaraés e 80 ha da cv. Marandu. Anteriormente a área era ocupada por soja e desde o plantio, há cerca de três anos, os capins não receberam nenhuma adubação.

Foram amostrados 20 pontos de cada cultivar e quantificados os componentes de produção de sementes: densidade de perfilhos reprodutivos por $\mathrm{m}^{2}$; número de rácemos por perfilho; comprimento dos rácemos; e número de espiguetas por rácemo.

O trabalho seguiu delineamento inteiramente casualizado, com 2 cultivares (capins Marandu e Xaraés) e 20 repetições. Aleatoriamente, seguindo trajetória em ziguezague, foram colocados quadrados de um metro quadrado e contados o número de perfilhos reprodutivos. De dois deles, foram contados o número de rácemos. O rácemo basal de cada perfilho foi medido com o auxílio de uma régua graduada e contadas as espiguetas. $\mathrm{Na}$ época apropriada, as sementes foram colhidas pelo método da varredura manual em 10 quadrados de um metro quadrado. 
A colheita de sementes na propriedade foi realizada por varredura mecanizada, iniciando-se no dia 22 de maio, estendendo-se até o dia 15 de junho de 2008. Para as avaliações experimentais foram coletadas 10 amostras em cada cultivar, sendo que na varredura manual a amostragem ocorreu em áreas de $1 \mathrm{~m}^{2}$, enquanto para a varredura mecanizada, diretamente da máquina. As amostras foram acondicionadas em sacos de papel com capacidade de um quilograma.

O peso bruto foi obtido pesando todo o material coletado em balança analítica. Em seguida, o material foi soprado, peneirado e realizado a separação manual a fim de retirar as impurezas. As sementes foram pesadas e obtido o peso de sementes puras. As impurezas foram obtidas por diferença de massas.

Para a realização do teste de Tetrazólio, utilizado para determinação das sementes vazias, mortas e viáveis foram utilizadas cinco repetições de 100 sementes puras tomadas ao acaso para cada combinação entre cultivar e método de colheita (BRASIL, 1992). Os dados obtidos foram transformados em arco seno raiz de $\mathrm{x}$, antes das análises, a fim de corrigir a normalidade dos dados.

As sementes coletadas foram transportadas ao laboratório de sementes da UNEB para condução das análises. As sementes foram armazenadas em sacos de papel de capacidade para $2 \mathrm{~kg}$, devidamente identificadas conforme o cultivar. Nesse período houve o preparo das sementes puras e da casa de vegetação para avaliação do vigor de plântulas pelo teste da caixa de areia, no mês de setembro de 2008.

O teste de vigor de plântulas é um teste de germinação com metodologia modificada, sendo aplicado algum tipo de estresse semelhante ao que possa limitar a emergência e fixação da plântula no campo (FAVORETTO, 1990).

Para a semeadura, foram utilizadas 16 bandejas de polietileno de $0,80 \times 0,40 \times 0,10 \mathrm{~m}$, com o substrato constituído de areia lavada e esterelizada, sendo peneirada em peneiras de 0,80 e $0,05 \mathrm{~mm}$, a fim de eliminar partículas grandes e pequenas. A areia passou pelo processo de esterilização em autoclave a $200^{\circ} \mathrm{C}$ por 2 horas (BRASIL, 1992). Após esse período, a areia foi deixada em temperatura ambiente para esfriar durante 24 horas. Foram utilizadas quatro repetições para cada combinação entre cultivar e método de colheita, sendo três linhas com 20 sementes por caixa. Em cada linha, as sementes foram semeadas às profundidades de 1,2 e $4 \mathrm{~cm}$. As bandejas foram colocadas em uma bancada dentro da casa de vegetação, mantendo-se a umidade similar à capacidade de campo.

Após 28 dias da semeadura (DAS), as plântulas foram contadas e cortadas com uma lâmina ao nível do solo. O material foi pesado em balança analítica com quatro casas decimais, obtendo-se a massa verde. Em seguida, o material foi levado à estufa a $105^{\circ} \mathrm{C}$ por um período de 24 horas. Após nova pesagem, foi obtido o peso seco.

Foram utilizados dois ensaios, ambos com delineamento inteiramente casualizado, em esquema fatorial. No primeiro ensaio foi utilizado um fatorial $2 \times 2$, sendo estudado o efeito da combinação entre duas cultivares de Brachiaria brizantha (Marandu e Xaraés), dois métodos de colheita (varredura manual e mecanizada). No segundo ensaio utilizaram-se um fatorial 2 x 3, avaliando-se os efeitos de dois métodos de colheita (varredura manual e mecanizada) com três profundidades de semeadura (1, 2 e $4 \mathrm{~cm})$. Os dados da germinação foram transformados em arco seno raiz de $x / 100$ e submetidos à análise de variância no Programa ASSISTAT (SILVA; AZEVEDO, 2006) comparando as médias pelo teste Tukey, a 5\% de probabilidade.

\section{Resultados e Discussão}

A densidade de perfilhos reprodutivos foi maior na cultivar Xaráes, que apresentou média de 206 perfilhos, em relação a cultivar Marandu, a qual apresentou média de 100 perfilhos (Tabela 1), uma superioridade de mais de $100 \%$, que influenciou diretamente a concentração de rácemos por área e, consequentemente, a produtividade de sementes. 
Tabela 1. Componentes da produção de sementes das cultivares Marandu e Xaraés de Brachiaria brizantha na fronteira agrícola do oeste da Bahia.

\begin{tabular}{lcccc}
\hline \multicolumn{1}{c}{$\begin{array}{c}\text { Componente da produção } \\
\text { de sementes }\end{array}$} & cv. Marandu & cv. Xaraés & DMS & C.V. $(\%)$ \\
\hline Densidade de perfilhos $\left(\mathrm{n}^{\mathbf{0}} / \mathrm{m}^{2}\right)$ & $100 \mathrm{~b}$ & $206 \mathrm{a}$ & 16,0 & 16,4 \\
Número de rácemos/perfilho & $6,80 \mathrm{~b}$ & $7,25 \mathrm{a}$ & 0,42 & 9,50 \\
Comprimento de rácemo $(\mathrm{cm})$ & $14,9 \mathrm{~b}$ & $15,8 \mathrm{a}$ & 0,65 & 6,57 \\
Número de espiguetas/rácemo & $50,5 \mathrm{a}$ & $51,1 \mathrm{a}$ & 2,60 & 8,02 \\
\hline
\end{tabular}

Médias seguidas de letras iguais na mesma linha não diferem pelo teste de Tukey a $5 \%$ de probabilidade.

${ }^{1}$ DMS = Diferença Mínima Significativa

${ }^{2}$ C.V. $=$ Coeficiente de variação.

Fonte: Elaboração dos autores.

A cv. Xaraés apresentou maior número e comprimento dos rácemos do que a cv. Marandu, indicando maior potencial para produção de sementes (Tabela 1). O comprimento dos rácemos basais obtidos neste trabalho (14,9 a 15,8 cm) foram superiores aos observados por Assis et al. (2003) $(8,7 \mathrm{~cm})$, entretanto estiveram na faixa de variação de 5 a $20 \mathrm{~cm}$ relatada por Soares Filho (1994).

É importante conhecer o comprimento dos rácemos, pois quanto maior o comprimento dos rácemos, maior o compartimento de produção de sementes e automaticamente maior capacidade a planta terá em produzi-las (FAVORETTO, 1990).

Por outro lado, o número de espiguetas por rácemos não variou $(50,8)$, independente da cultivar
(Tabela 1). Os valores obtidos neste trabalho foram superiores aos 32,1 unidades/rácemo, observados por Assis et al. (2003), para B. brizantha, provavelmente pela avaliação ter sido realizada no campo de produção de sementes, sendo aplicados tecnologia de produção, diferentemente ao relatado por esses autores, que realizaram avaliações no banco de germoplasma da EMBRAPA Gado de Corte.

O rendimento de sementes puras + impurezas colhidas manualmente não diferiu entre os cultivares (Tabela 2). As produtividades observadas neste trabalho foram inferiores a 650 e $534 \mathrm{~kg} /$ ha estimados por Quadros et al. (2010) para os cvs. Xaraés e Marandu cultivados na região oeste da Bahia.

Tabela 2. Rendimento de sementes colhidas por varredura manual dos cvs. Marandu e Xaraés na fronteira agrícola do oeste da Bahia.

\begin{tabular}{lcc}
\hline \multicolumn{1}{c}{ Produção de sementes } & cv. Marandu & cv. Xaraés \\
\hline Rendimento de sementes puras + impurezas (kg/ha) & 434,6 a $(100)$ & 437,7 a $(100)$ \\
Rendimento de impurezas (kg/ha) & 279,9 a $(64,4)$ & $249,6 \mathrm{~b}(57,0)$ \\
Rendimento de sementes puras (kg/ha) & $154,7 \mathrm{~b}(35,6)$ & $188,2 \mathrm{a}(43,0)$ \\
\hline
\end{tabular}

Os valores em parênteses correspondem em percentual.

Médias seguidas de letras iguais na mesma linha não diferem pelo teste de Tukey a 5\% de probabilidade.

Fonte: Elaboração dos autores.

Contudo, a quantidade de impurezas foi maior no cv. Marandu que o cv. Xaraés. Retiradas as impurezas, o rendimento sementes puras no cv. Xaraés foi $21 \%$ superior, em relação ao cv. Marandu
(Tabela 2), corroborando com Quadros et al. (2010). Porém, em valores absolutos, apresentaram-se abaixo da faixa de $650 \pm 300 \mathrm{~kg} / \mathrm{ha}$ citados por Souza (1999) para a cvs. Marandu e La Libertad de 
B. brizantha, considerando a colheita no chão, pelo método da varredura, e, superiores aos $80-120 \mathrm{~kg} / \mathrm{ha}$ de sementes puras nos cvs. Marandu e Xaraés de $B$. brizantha, relatados por Lima (2007).

Em Queensland, Austrália, quando as condições são otimizadas, ocasionalmente a produção de sementes puras de B. decumbens alcança 1000 $\mathrm{kg} / \mathrm{ha}$, fruto do acúmulo de sementes caídas e da colheita combinada (HOPKINSON; SOUZA; DIULGHEROFF, 1996).

Os cvs. Marandu e Xaraés apresentaram percentual semelhante de sementes viáveis, independente do tipo de colheita ser por varredura manual ou mecanizada (Tabela 3). A média geral foi de $68,4 \%$, considerada satisfatória.

Tabela 3. Percentual de sementes viáveis, vazias e mortas dos cultivares Marandu e Xaráes colhida por varredura manual e mecanizada.

\begin{tabular}{ccccc}
\hline \multirow{2}{*}{ Classificação da semente } & \multicolumn{2}{c}{ cv. Marandu } & \multicolumn{2}{c}{ cv. Xaraés } \\
\cline { 2 - 5 } & Manual & Mecanizada & Manual & Mecanizada \\
\hline Sementes viáveis (\%) & $64,6 \mathrm{a}$ & $68,2 \mathrm{a}$ & $72,2 \mathrm{a}$ & $68,6 \mathrm{a}$ \\
Sementes vazias (\%) & $26,0 \mathrm{a}$ & $16,8 \mathrm{c}$ & $23,6 \mathrm{ab}$ & $19,4 \mathrm{bc}$ \\
Sementes mortas (\%) & $9,4 \mathrm{ab}$ & $8,2 \mathrm{a}$ & $11,0 \mathrm{ab}$ & $12,0 \mathrm{~b}$ \\
\hline
\end{tabular}

Médias seguidas de letras iguais na mesma linha não diferem pelo teste de Tukey a 5\% de probabilidade.

Fonte: Elaboração dos autores.

Por outro lado, houve diferença entre o método de colheita na quantidade de sementes vazias, provavelmente porque o sistema de varredura/ aspiração da máquina acabe não sugando uma massa muito grande de sementes vazias, o que não ocorre com a varredura manual, que é feita mais cuidadosamente.

Na primeira operação da varredura mecanizada, a máquina varre sementes e outros materiais do solo para as peneiras na limpeza primária, atingindo $20 \mathrm{a}$ $30 \%$ de pureza. Todavia, em cultivos em linha sobre solos argilosos, a eficiência de recuperação pode ser maior que 95\% de sementes puras (LOCK; SOUZA, 1999). Segundo esses autores, em $B$. decumbens e $B$. brizantha, o corte, a varredura e a peneiragem pode levar manualmente 75 a 90 homens/ha/dia, enquanto a máquina com vassouras rotativas cobre 2 a 3 ha/ dia. A varredura manual é usual para fazendeiros de pequena escala, recuperando grande proporção de sementes caídas após abscisão, as quais apresentam qualidade (ILCA, 1994).

Quanto à germinação, não houve diferença significativa entre os cultivares, formas de colheita (varredura manual ou mecanizada), ou as profundidades utilizadas. Torres e Lenne (1988), estudando sementes de Brachiaria dictyoneura sob colheita mecânica e na inflorescência, sem ou com o período de "cura", demonstrou não existir diferenças significativas entre os métodos de colheita (Tabela 4). Semelhantemente, Cardozo, Sánchez e Ferguson (1991) verificaram que a germinação das sementes de Brachiaria dictyoneura cv. Lanero não foi influenciada pelos métodos de colheita (na inflorescência e por varredura). 
Tabela 4. Percentual de germinação de sementes e vigor de plântulas dos cvs. Xaráes e Marandu colhidas por varredura manual ou mecanizada, semeadas sob diferentes profundidades em caixa de areia.

\begin{tabular}{|c|c|c|c|c|c|c|}
\hline \multirow{2}{*}{ Cultivar } & \multicolumn{3}{|c|}{ Manual } & \multicolumn{3}{|c|}{ Mecanizado } \\
\hline & $1 \mathrm{~cm}$ & $2 \mathrm{~cm}$ & $4 \mathrm{~cm}$ & $1 \mathrm{~cm}$ & $2 \mathrm{~cm}$ & $4 \mathrm{~cm}$ \\
\hline \multicolumn{7}{|c|}{ Germinação (\%) } \\
\hline cv. Marandu & 53,7 & 53,7 & 48,7 & 58,7 & 56,2 & 46,2 \\
\hline cv. Xaraés & 53,7 & 55,0 & 48,7 & 53,7 & 57,5 & 42,5 \\
\hline Média & $53,7 \mathrm{a}$ & $54,3 \mathrm{a}$ & $48,7 \mathrm{a}$ & $56,2 \mathrm{a}$ & $56,8 \mathrm{a}$ & $44,3 \mathrm{a}$ \\
\hline \multicolumn{7}{|c|}{ Vigor de plântula (mg MS/plântula) } \\
\hline cv. Marandu & 90 & 90 & 67 & 100 & 95 & 77 \\
\hline cv. Xaraés & 77 & 90 & 77 & 110 & 97 & 75 \\
\hline Média & $83 \mathrm{a}$ & $90 \mathrm{a}$ & $73 \mathrm{~b}$ & $105 \mathrm{a}$ & $96 \mathrm{a}$ & $76 \mathrm{~b}$ \\
\hline
\end{tabular}

Médias seguidas de letras iguais na mesma linha não diferem pelo teste de Tukey a 5\% de probabilidade.

Fonte: Elaboração dos autores.

Os resultados de germinação deste trabalho foram inferiores aos observados por Bonome et al. (2006), estudando efeito do condicionamento osmótico em sementes de Brachiaria brizantha cv. Marandu (68,92\%), provavelmente pelo teste na caixa de areia apresentar condições simulando às do campo, menos favoráveis à germinação.

Alguns autores apontam baixa germinação de sementes de capim devido à dormência tegumentar, portanto recorrem a métodos de escarificação para melhorar os índices germinativos (GARCIA; CÍCERO, 1992). Segundo Castro et al. (1996), métodos que utilizam escarificação química, térmica e mecânica são capazes de quebrar a dormência de Brachiaria decumbens Stapf., com maior eficiência. Na escolha do método deve-se levar em consideração sua influência sobre sanidade das sementes, como demonstrado por Martins, Silva e Almeida (2001) em sementes de B. brizantha cv. Marandu submetidas aos tratamentos térmicos secos e químicos com ácido sulfúrico $\left(\mathrm{H}_{2} \mathrm{SO}_{4}\right)$.

$\mathrm{O}$ vigor das plântulas, indicado pela massa seca das mesmas, não foi influenciado pelo cultivar ou método de colheita, mas foi influenciado pela profundidade de semeadura (Tabela 4). A semeadura a $4 \mathrm{~cm}$ reduziu o vigor das plântulas, em relação à semeadura a 1 e $2 \mathrm{~cm}$.
Os resultados de vigor de plântula observados neste trabalho se aproximam da faixa de 90 à 199 mg MS/plântula obtidos por Almeida et al. (2009), ao analisarem seis diferentes marcas comerciais de sementes vendidas no mercado varejista de Barreiras, Bahia.

Lotes de sementes apresentando maior peso médio por plântulas são os mais vigorosos, propiciando melhor estabelecimento da pastagem (FAVORETTO, 1990).

\section{Conclusões}

A cv. Xaraés de B. brizantha foi superior à cv. Marandu em todos os componentes da produção de sementes, exceto no número de espiguetas por rácemo, resultando em maior produtividade de sementes.

O cv. Xaraés apresentou maior produtividade de sementes puras do que a cv. Marandu, enquanto o percentual de sementes viáveis foi semelhante entre as cultivares e o método de colheita empregado.

A germinação na caixa de areia não diferenciou entre cultivares, método de colheita, ou a profundidade de semeadura. Contudo, o vigor de plântula reduziu com o aumento da profundidade de semeadura de 1 e $2 \mathrm{~cm}$ para $4 \mathrm{~cm}$. 


\section{Agradecimentos}

Agradecemos a Fazenda Sagrillo pela permissão da utilização dos campos de produção de sementes para a realização das avaliações.

\section{Referências}

ASSOCIAÇÃO DOS IRRIGANTES DA BAHIA AIBA. $2^{\circ}$ Levantamento safra 2010/11 oeste da Bahia. 2011. Disponível em: <www.aiba.org.br>. Acesso em: 15 abr. 2011.

Histórico de safras. 2009. Disponível em: <www.aiba.org.br>. Acesso em: 15 jul. 2009.

ALMEIDA, J. A. R.; QUADROS, D. G.; SÁ, A. M.; CARDOSO, J. A.; SANTOS, S. N. Vigor de sementes de Brachiaria brizantha $\mathrm{cv}$. Marandu comercializadas em Barreiras - BA. In: CONGRESSO INTERNACIONAL DO BOI DE CAPIM, 4., 2009, Salvador. Anais... Salvador: GT5, 2009. CD-ROM.

ANDRADE, R. P. Tecnologia de produção de sementes de espécies do gênero Brachiaria. In: SIMPÓSIO SOBRE O MANEJO DA PASTAGEM, 11., 1994, Piracicaba. Anais... Piracicaba: FEALQ, 1994. p. 49-66.

ASSIS, G. M. L.; EUCLYDES, R. F.; CRUZ, C. D.; VALLE, C. B. Discriminação de espécies de Brachiaria baseada em diferentes grupos de caracteres morfológicos. Revista Brasileira de Zootecnia, Viçosa, MG, v. 32, n. 3, p. 576-584, 2003.

BONOME, L. T. S.; GUIMARÃES, R. M.; OLIVEIRA, J. A.; ANDRADE, V. C.; CABRAL, P. S. Efeito do condicionamento osmótico em sementes de Brachiaria brizantha cv. Marandu. Ciência Agrotécnica, Lavras, v. 30, n. 3, p. 422-428, 2006.

BRASIL. Ministério da Agricultura e Reforma Agrária. Regras para análise de sementes. Brasília: SNDA/ DNDV/CLAV, 1992. 365 p.

CARDOZO, C. I.; SÁNCHEZ, M.; FERGUSON, J. E. Efecto del método de cosecha en el rendimiento y calidad de las semillas de Brachiaria dictyoneura cv. Llanero. Pasturas Tropicales, Cali, v. 13, n. 1, p. 9-17, 1991.

CASTRO, C. R. T.; CARVALHO, W. L.; REIS, F. P.; BRAGA FILHO, J. M. Superação da dormência tegumentar em sementes de Brachiaria de decumbens Stapf. Revista Ceres, Viçosa, v. 43, n. 245, p. 64-75, 1996.

EUCLIDES, V. P. B.; VALLE, C. B.; MACEDO, M. C. M.; ALMEIDA, R. G.; MONTAGNER, D. B.; BARBOSA, R. A. Brazilian scientific progress in pasture research during the first decade of XXI century. Revista
Brasileira de Zootecnia, Viçosa, MG, v. 39, p. 151-168, 2010. Suplemento especial.

FAVORETTO, V. Considerações sobre época de colheita de sementes de gramíneas forrageiras. In: ENCONTRO SOBRE PRODUÇÃO DE SEMENTES DE PLANTAS FORRAGEIRAS, 4., 1990, São Paulo. Anais... São Paulo: Instituto de Zootecnia, 1990, p. 1-29.

GARCIA, J.; CÍCERO, S. M. Superação de dormência em sementes de Brachiaria brizantha cv. Marandu. Scientia Agricola, Piracicaba, v. 49, n. 1, p. 9-13, 1992.

HOPKINSON, J. M.; SOUZA, F. H. D.; DIULGHEROFF, S. Reproductive physiolopgy, seed production, and seed quality of Brachiaria. In: MILES, J. W.; MAASS, B. L.; VALLE, C. B. et al. (Ed.). Brachiaria: biology, agronomy, and improvement. Cali/Campo Grande: CIAT/EMBRAPA. 1996. p. 124-140.

INTERNATIONAL LIVESTOCK CENTRE FOR AFRICA - ILCA. Forage seed production. Addis Ababa: ILCA. 1994. 70 p. Disponível em: <http://www.fao.org/ sd/erp/toolkit/BOOKS/forage_Seed_production.pdf $>$. Acesso em: 07 maio 2011.

JOSÉ, M. R. Sementes de forrageiras tropicais: pontos importantes da produção. Seed News, Pelotas, v. 13, n. 3, p. 28-31, 2009.

LIMA, A. E. S. Condicionamento osmótico de sementes de Brachiaria brizantha (Hochst. ex A. Rich) Stapf. 2007. Dissertação de Mestrado (Biologia Vegetal) Universidade Federal de Mato Grosso do Sul, Campo Grande.

LOCK, D. S.; SOUZA, F. H. D. Seed haversting and drying: grasses. In: LOCH, D. S.; FERGUSON, J. E. Forage seed production vol. 2: tropical and subtropical species. Wallingford: CABI. 1999. p. 191-211.

MARTINS, L.; SILVA, W. R.; ALMEIDA, R. R. Sanidade de sementes de Brachiaria brizantha (Hochst. ex A. Rich) Stapf submetidas a tratamentos térmicos e químico. Revista Brasileira de Sementes, Brasília, v. 23, n. 2, p. 117-120, 2001.

MASCHIETTO, R. W.; NOVEMBRE, A. D. L. C.; SILVA, W. R. Métodos de colheita e qualidade de sementes de capim colonião cultivar Mombaça. Bragantia, Campinas, v. 62, n. 2, p. 291-296, 2003.

OLIVEIRA, D. N. S.; QUADROS, D. G.; SKOWRONSKI, J.; VIEIRA, G. A.; OLIVEIRA, G. L. Avaliação dos métodos de colheita e beneficiamento de sementes de gramíneas forrageiras no oeste da Bahia. In: CONGRESSO INTERNACIONAL DA PRODUÇÃO PECUÁRIA, 1., 2010, Salvador. Anais... Salvador: GT5, 2010. CD-ROM. 
QUADROS, D. G.; SKOWRONSKI, J.; VIEIRA, G. A.; OLIVEIRA, G. L.; MOSCON, E. S.; OLIVEIRA, D. N. $\mathrm{S}$. Análise do perfil da produção e a produtividade de sementes de gramíneas forrageiras no oeste da Bahia. In: REUNIÃO ANUAL DA SOCIEDADE BRASILEIRA DE ZOOTECNIA, 47., 2010, Salvador. Anais... SBZ: Salvador, 2010. CD-ROM.

SILVA, F. A. S. E.; AZEVEDO, C. A. V. A new version of the assistat-statistical assistance software. In: WORLD CONGRESS ON COMPUTERS IN AGRICULTURE, 4., 2006, Orlando. Anais... Orlando: American Society of Agricultural Engineers, 2006. p. 393-396.
SOARES FILHO, C. V. Recomendações de espécies e variedades de Brachiaria para diferentes condições. In: SIMPÓSIO SOBRE MANEJO DA PASTAGEM, 11., 1994, Piracicaba. Anais... FEALQ: Piracicaba, 1994. p. 2548.

SOUZA, F. H. D. Brachiaria spp. in Brazil. In: LOCH, D. S.; FERGUSON, J. E. Forage seed production vol. 2: tropical and subtropical species. Wallingford: CABI. 1999. p. 371-379.

TORRES, R.; LENNE, J. M. Efecto de los métodos de cosecha y secado de la semilla de Brachiaria dictyoneura en su microflora y calidad (viabilidad y germinación). Acta Agronomica, Bogotá, v. 38, n. 2, p. 20-34, 1988. 
